\title{
Ett fall av kulturspecifik referens: översättningen till franska av det svenska ordet lingon
}

\author{
Av Olof Eriksson, professor i franska
}

Den problematik som är förknippad med översättning av kulturspecifika ord har under senare år rönt stor uppmärksamhet bland översättningsforskare. Det har framför allt handlat om att analysera de strategier som står till en översättares förfogande när det gäller att med minsta möjliga förlust av "dynamik" på översättningsspråket uttrycka begrepp som där saknar direkt referentiell motsvarighet.

Den typ av ord som det här rör sig om benämns av Newmark (1988, s. 95) "cultural words", en term som har sin grund i det faktum att varje enskild språkgemenskap utgör vad Mounin (1990, s. 59-68) kallat en "monde culturel" i vilken en större eller mindre del av begreppsuppsättningen är specifik för språkgemenskapen i fråga och därmed kräver beteckningar som blir svåra eller rentav omöjliga att återge på andra språk. Mounin (s. 65) ger bland annat som exempel de oöverstigliga svårigheter som det skulle erbjuda att få innevånarna i den tropiska regnskogen kring Amazonfloden att förstå innebörden av ett ord som öken eller de likaledes oöverstigliga problem som det skulle innebära att försöka återge beteckningar på franska och italienska kulturspecifika ostsorter i italiensk respektive fransk översättning, trots att det här rör sig om två "civilisations" som ligger varandra relativt nära.

Dessa kulturspecifika ord får inte förväxlas, vilket Mounin anklagar många forskare (bl.a. Nida och Vinay \& Darbelnet) för att ha gjort, med de lexikala skillnader mellan språk som är resultatet av att man i olika kulturer har olika "visions du monde", till exempel i sättet att med språkliga beteckningar göra olika uppdelningar av färgskalan eller att, som i eskimåspråken, ha en rad olika beteckningar för olika varieteter av begreppet 'snö', där ett språk som franska egentligen endast har en enda - neige -, med generell innebörd. Det handlar i detta senare fall emellertid inte om begrepp som saknas i andra kulturer utan om begrepp som har olika referentiell status i de jämförda kulturerna.

Den mest radikala strategin i detta sammanhang är den som Vinay \& Darbelnet (1977, s. 52-54; 258-266) betecknar med den mycket omdiskuterade termen adaptation, vars diffusa innebörd har påpekats av åtskilliga översättningsforskare, till exempel Newmark (1988, s. 90-91). En adaptation består i att man i översättningen försöker finna ett "cultural word" (dvs. ett kulturspecifikt ord) som hos läsaren av översättningstexten kan förväntas ge upphov till konnotativa associationer som ligger nära dem som originaltextens ord väcker hos läsaren av denna text. Newmark talar här om "cultural equivalent" och ger som exempel franskans pause-café för att återge engelskans tea break. Bland exempel från Vinay \& Darbelnet kan nämnas den kända översättningen av engelskans cricket med dess påstådda franska "kulturella motsvarighet" Tour de France. Mounin ifrågasätter till och med om en sådan radikal strategi ens kan betraktas som en översättning: "Traduit-on vraiment vigne quand on substitue à cette notion tel mot désignant une plante qui ressemble à la vigne botaniquement, mais qui n'est pas cultivée, et ne donne pas de fruit non plus?"

Benämningen adaptation hos Vinay \& Darbelnet omfattar emellertid också den strategi som består i att översättaren tillgriper ett ord/uttryck som med Newmarks terminologi inte är att betrakta som "cultural", det vill säga inte har kulturspecifik status. Detta innebär att översättaren så att säga "avkulturaliserar" ("deculturalises"; s. 83) originaltextens ord. Newmark använder för att beteckna denna process termen neutralisation (s. 103) och termen functional equivalent för att beteckna resultatet av processen. Dessa översättningar 
får ofta en parafraserande karaktär och kräver i allmänhet ett språkligt uttryck som inte inskränker sig till ett enda ord. Bland Newmarks exempel kan nämnas 'French secondary school leaving exam' som översättning av franskans baccalauréat (s. 83) (jfr Mounin s. 63, med exempel från Nida).

En adaptation är hos Vinay \& Darbelnet antingen obligatorisk eller fakultativ. Andra forskare använder denna term med en delvis annorlunda och mera begränsad innebörd. För Svane (1998, s. 99), till exempel, är en adaptation definitionsmässigt obligatorisk, medan hon med termen conversion avser en översättningsstrategi som trots att den oftast är mera radikal än adaptationen (t.ex.: la soupe quotidienne > husmanskost) likväl inte är obligatorisk. Tillyttermeravisso kan den alltid obligatoriska adaptationen, enligt Svane, vara antingen semantiskt (t.ex.: shallow/grund > peu profond) eller referentiellt (mairie > stadshus, rådhus eller skattemyndighet beroende på kontexten) motiverad. I det förra fallet talar Vinay \& Darbelnet om modulation ("changement de point de vue": grund = 'föga djup'), medan adaptation hos dem utgör den samlande beteckningen för en fakultativ conversion och en obligatorisk referentiell adaptation. Det råder alltså på detta område som på så många andra - en ganska stor begreppsmässig och terminologisk förvirring.

En semantisk kategori som upplåter sig sällsynt väl för studiet av de kulturspecifika ordens översättningsstrategier är olika språksamhällens flora. Här finns också ofta en direkt koppling mellan det kulturspecifika och det naturspecifika i så måtto att för en språkgemenskap specifika växter ofta ingår i maträtter som utgör ett viktigt inslag i denna språkgemenskaps specifika matkultur. I den förteckning som Newmark ger (s. 103) över de kulturspecifika ordens semantiska områden hamnar båda dessa företeelser - växter och mat - med etiketterna ecology respektive material culture under den samlande rubriken Culture ("Way of life and its manifestations peculiar to one speech community").

Bland växterna uppvisar ofta bärväxterna, på grund av skillnader vad beträffar topografi, klimat och andra naturförhållanden, en särskilt hög grad av kulturell specificitet, vilken naturligtvis avspeglar sig i betydande terminologiska skillnader mellan språken.

Ett särskilt intressant språkligt fall, vid översättning från svenska till franska, erbjuder det bär som på svenska benämns lingon. Detta måste, i förhållande till Frankrike, betraktas som i hög grad natur- och kulturspecifikt för Sverige (eller Skandinavien utom Danmark). Även om bäret i Frankrike kan påträffas i ringa kvantitet i Centralmassivet och i Alperna [1], så torde det för nästan alla fransmän ändå vara helt okänt som ett bär ingående i Frankrikes flora. Till detta kommer den oerhört viktiga kulturhistoriska roll som lingonet spelat i Sverige i egenskap av en av de mest karakteristiska inslagen i svensk mathushållning och svensk matkultur. Om denna roll kan man läsa i Bärboken (Armfelt Hansell 1969, s. 243250) och i ett stort antal specialstudier i ämnet (t.ex. Wikmark 1907, Ericsson 1934, Eriksson-Ingelög-Kardell 1979, Kardell-Carlsson 1982).

Följande schema kan tjäna som utgångspunkt för framställningen:

$$
\text { blåbär }\left\{\begin{array}{l}
=\text { myrtille }(>\text { myrtille rouge (sauvage })=\text { lingon }) \\
=\text { airelle }>\text { airelle rouge }=\text { lingon }>=\text { airelle }\left\{\begin{array}{l}
=\text { blåbär }>=\text { airelle myrtille } \\
=\text { lingon }
\end{array}\right.
\end{array}\right.
$$

blåbär $=$ [airelle $]$ myrtille

lingon $=$ airelle [rouge $]$

Det finns således i franskan huvudsakligen två ord [2] för att beteckna blåbäret, vilket, till skillnad från lingonet, är vanligt förekommande i Frankrike, både naturellt och kulturellt (sylt, sorbet etc.). Strikt botaniskt är airelle en släktbeteckning (vaccinium) och myrtille en artbeteckning (Dauzat et al. 1964, s. 19), men i bruket är det fråga om två likvärdiga och synonyma beteckningar på blåbäret, vilket klart framgår av lexikonuppgifter som de följande: "airelle. Genre d'éricacées, appelées aussi myrtille dont les fruits noir violacé, 
aigrelets, servent à faire des siropes." (Dictionnaire Actuel de la Langue Française, 1991, s. 29); "airelle [...] 2. Par extens. Fruit de cet arbrisseau (dit aussi myrtille)" (Grand Larousse de la Langue Française, t. I, 1971, s.109); "airelle nf. Région. Myrtille" (Dictionnaire Hachette de la Langue Française, 1980, s. 38); "airelle [...] le fruit est une petite baie noire et sphérique savoureuse, baie appelée également airelle. Famille des éricacées.) [Syn. BRIMBELLE, MYRTILLE]." (LEXIS, 1975, S. 51); "airelle. Nom méridional de la myrtille" (Micro Robert, 1971, s. 26); "airelle [...] les fruits sont encore appelés myrtilles" (Pluridictionnaire, 1975, s. 32); "airelle [...] nf (myrtille) bilberry, whortleberry, blueberry" (Le Robert \& Collins Dictionnaire français-anglais, 1987, s. 19); "Il [sc. le mot airelle] continue d'être en concurrence avec d'autres noms de cette baie ou de baies semblables, comme myrtille, qui paraît plus courant en français central" (Le Robert. Dictionnaire Historique de la Langue Française, t. I, 1992, s. 40).

Som redan framgår av några av dessa citat, är fördelningen av de båda ordens användning geografiskt betingad, på så sätt att airelle är den sydfranska beteckningen, vars utbredningsområde är starkt begränsat och som tillyttermeravisso är på väg att utkonkurreras av myrtille: "Dans l'usage courant airelle est le terme du Midi, myrtille celui du Nord, 'qui élimine peu à peu les mots régionaux'." (Trésor de la Langue Française, 1973, s. 385)

Ordet airelle, som är av betydligt yngre datum än myrtille (slutet av 1500-talet), har också följdriktigt occitanskt ursprung. Det kommer via en avledd form airelo, belagd i

Cevennerna i Centralmassivet, från provensalskans aire, av femininformen (atra) av det latinska adjektivet ater 'svart' (jfr t.ex. F.E.W., 1928, s. 166; Bloch-Wartburg, 1968, s. 16; T.L.F., 1973, s. 385; Dictionnaire Historique de la Langue Française, 1992, s. 40; Grand Dictionnaire Encyclopédique Larousse, 1982, s. 231; Dauzat et al., 1964, s. 19).

För att beteckna det bär som i svenskan kallas lingon, och som ju trots allt i begränsad omfattning förekommer i Frankrike och som importeras dit, har nu franskan, på basis av likhets- och släktskapsprinciperna, skapat den adapterade formen airelle (à/aux fruits) rouge(s): airelle rouge (Le Robert Méthodique, 1982, s. 32); airelle à fruits rouges (Duden Français, 1981, s. 662; Le Nouveau Petit Robert, 1995, s. 51); airelle aux fruits rouges (= airelle vigne du Mont-Ida < vaccinium vitis-idaea) (Le Grand Robert, t. I, 1989, s. 222), vilken svenska (och andra skandinaviska) lexikografer inte varit sena att anamma som översättning av svenskans lingon (eller danskans tyttebcr): "airelle rouge lingon" (Zenk, 1992, s. 10); "airelle à fruits rouges lingon" (Enwall-Lötmarker, 1995, s. 23); "lingon airelle rouge" (Norstedts Franska Ordbok, 1991, s. 233); "tyttebær airelle à fruits rouges, airelle rouge" (Blinkenberg-Høybye, 1991, s. 1789); "airelle rouge lingon" (Schlyter, 1992, s. 80); "lingon airelle rouge" (Schulthess, 1886, s. 285).

Det är intressant att notera i detta sammanhang att man i Grand Robert Encyclopédique (1982, s. 231) finner airelle rouge inte som beteckning utan som beskrivning, och med den adapterade formen airelle de Scandinavie som beteckning: "Airelle [...] petite baie comestible noire (myrtille) ou rouge (airelle de Scandinavie)."

Den typ av adaptation vi har att göra med i fallet airelle rouge skulle man kunna benämna intern lexikaliserad adaptation, eftersom den inte är direkt kopplad till översättningsprocessen. Faktum är att jag inte lyckats belägga formen airelle rouge som översättning av lingon i någon enda litterär text.

Den form som i stället uppträder i översättningar till franska av svenska litterära texter är airelle. Här har alltså skett en utveckling genom vilken airelle har tappat sitt preciserande efterled men samtidigt likafullt behållit betydelsen av lingon. Denna utveckling har möjliggjorts av ordet airelle's ringa geografiska utbredning i Frankrike och av dess för de flesta fransmän okända betydelse; detta i en situation där det redan fanns ett väl etablerat ord - myrtille - för att beteckna blåbäret [3].

Men även utanför översättningslitteraturens område kan man konstatera att airelle idag är 
det vedertagna ordet för att beteckna lingonet. Det är exempelvis det ord som konsekvent förekommer på franska matsedlar: civet de chevreuil aux airelles, rôti de biche aux airelles, etc. [4]

Ordet airelle har således kommit att beteckna ett begrepp som hade behov av en beteckning i form av ett enkelt icke parafraserande och icke motsägelsefullt lexem ('ett bär som är blått kan inte samtidigt vara rött'), vilket var möjligt därför att airelle hade en betydelse som inte var tillräckligt etablerad för att ordet inte skulle kunna upplåta sig åt en ny betydelse.

Lexika, till skillnad från översättningstexter, har emellertid, som så ofta, varit mycket långsamma med att registrera denna nya betydelse. Av franska lexika har jag bara funnit den i Le Nouveau Petit Robert, vars första utgåva daterar sig till 1993 och där det under airelle som andra betydelse (den första är beteckningen på busken) står att läsa: "Baie rouge de cet arbrisseau" (s. 51). I alla utgåvor av Le Petit Robert fram till 1993 förekommer emellertid inte denna uppgift. Av tvåspråkiga ordböcker ger Vising (1936, s. 16) för airelle betydelsen "lingon[ris]", dock med tillägget "(= rouge)".

I litterära översättningstexter är emellertid sedan lång tid tillbaka airelle den gängse översättningen av lingon. Här följer ett antal exempel som belyser detta:

(1) Han älskade bärtiden. Då fick han sälja. Han älskade blåbär och lingon, särskilt lingon om de voro många. (Martinson, Nässlorna blomma 47)

Il adorait la saison des baies. Alors il vendait. Il adorait les myrtilles et les airelles, les airelles surtout - quand elles étaient en abondance. (70)

(2) Ett lok hade fem öppna vagnar med lingon efter sig, ett kom pustande med en lång rad bölande kreatursvagnar. (Lagerkvist, Gäst hos verkligheten 59)

Une locomotive tirait cinq wagons plats pleins d'airelles, une autre arriva en haletant avec un long convoi de bêtes beuglantes. (58)

(3) En kvinna går där nedböjd över tuvorna och plockar lingon. (Moberg, Sömnlös 347)

Une femme penchée sur les buissons cueille des airelles. (304)

(4) Till och med om en lämnar boskap och folk i fred och bara lever av lingon och myror och grönt, så får en inte bo kvar i skogen. (Lagerlöf, Nils Holgersson 362)

Même si nous laissons les gens et le bétail en paix et ne vivons plus que d'airelles, de fourmis et de verdure, ils ne nous permettent plus de vivre dans la forêt. (3856)

(5) Hon hade stoppat lingon i munnen medan hon plockade. (Moberg, Sömnlös 349)

Elle avait mangé des airelles pendant sa cueillette. (306)

(6) Över stugdörren hängde krans och krona i lingonris och prästkragar och på ömse sidor stodo björkruskor. (Strindberg, Hemsöborna 98)

Le portail était flanqué de deux ramées de bouleau, surmonté d'une guirlande et couronné d'airelles et de marguerites. (115-6)

(7) Henrik stannade då bilen, sprang ut och kastade sig raklång på rygg bland lingonriset. (Wägeus, Jakt på ett vitt fält 15)

A ce moment-là Henrik a arrêté l'auto, et il en a sauté pour aller se jeter de tout son long sur le dos au milieu des airelles. (18) 
Redan i en bok från 1922 om Sverige (Bellessort) görs distinktionen mellan myrtille och airelle: "Elle (sc. L'île) est pauvre : il n'y pousse que des myrtilles et des airelles." (s. 84)

Det är emellertid obestridligt att ordet airelle regionalt i Frankrike har kvar betydelsen 'blåbär'. Det är därför inte att förvåna sig över att man velat betona den etymologiska grundbetydelsen hos airelle (< atra 'svart') genom att, i analogi med bildningen airelle rouge, till airelle foga ett preciserande myrtille. Denna form är vanligt förekommande under uppslagsordet airelle i tvåspråkiga lexika, men det är symptomatiskt att man oftast i dessa lexika under uppslagsordet blåbär finner endast myrtille och under myrtille endast 'blåbär'. Airelle myrtille skall alltså ses som en skapelse som tillkommit i opposition till airelle rouge. Exempel på dylika lexika är Zenk: "airelle myrtille blåbär", men: "blåbär myrtille" och "myrtilles pl. blåbär"; Enwall-Lötmarker: "airelle myrtille blåbär", men: "myrtille blåbär"; Schlyter: "la myrtille (l'airelle f. myrtille) blåbär"; Norstedts: "airelle [myrtille] blåbär", men: "blåbär myrtille"; Blinkenberg-Høybye (1964, s. 45): "airelle [...] (= myrtille) bølle, blåbær" — (1991, s. 163): "blåbær myrtille".

Men beteckningen förekommer också i enspråkiga franska lexika, till exempel i Le Robert Méthodique (s. 32), Le Nouveau Petit Robert (s. 51), Le Grand Robert (s. 222). I inga av dessa nämns emellertid kombinationen airelle myrtille under uppslagsordet myrtille.

Det som är gemensamt för de hittills nämnda två- eller flerledade adapterade bildningarna är att de har en beskrivande valör: lexemet airelle rouge talar sålunda om att det är fråga om ett bär som har ungefär samma storlek och form som ett blåbär men som skiljer sig från detta genom att ha röd färg. Det finns, när det gäller lingon, andra liknande bildningar, men som inte uppnått samma grad av lexikalisering. Exempelvis återges lingon i Strindbergs Hemsöborna med myrtille rouge (8), och i en bok om Sverige av François-Régis Bastide talas det i betydelsen lingon om myrtille sauvage (9), en bildning som förutom att ha låg lexikaliseringsgrad dessutom har en beskrivande valör som är mindre precis (skulle det alltså finnas myrtilles som inte är sauvages?):

(8) [...] och hon tog sig till att plocka lingon i förklät, för hon kunde inte vara sysslolös. (Strindberg, Hemsöborna 75)

[...] elle revint par le bois où elle s'attarda à ramasser des myrtilles rouges qu'elle rapporta dans son tablier. (88)

(9) Le dîner du soir est relativement "continental", bien que certains plats suédois surprennent l'étranger. Les köttbullar, boules de viande frites, humectées par une gelée de myrtilles sauvages (lingon), l'ärtsoppa, soupe de pois jaunes, au lard et au punch, sont les plus savoureux. (Bastide, Suède 95)

Dessa båda egenskaper - låg lexikaliseringsgrad och svag beskrivningsvalör - utmärker också översättningarna av andra bärsorter, med ännu högre kulturspecificitet, till exempel hjortron, som i Norstedts lexikon återges med mûre boréale och hos Blinkenberg-Høybye (s. 1090) [hjortron = multebær] med "[espèce de] mûre sauvage". Hos svenska lexikografer som Schulthess, Hammar och Zenk återges det med fausse-mûre, en beteckning som således visserligen uppnått en viss lexikaliseringsgrad men som praktiskt taget saknar beskrivande värde och där förledet fausse har sin vanliga uppgift att "désigner une chose ayant une certaine ressemblance [...] avec la chose proprement désignée par le substantif" (T.L.F., t. 8, 1980, s. 701). Det är en tom etikett på ett i Frankrike ej förekommande bär och ordet kan mycket riktigt inte heller återfinnas ens i de mest utförliga enspråkiga franska lexika. Möjligen kan det ha sitt ursprung hos översättare snarare än lexikografer. Det påträffas nämligen ofta i litterära texter:

(10) [...] och dalgången var betäckt med en tjock matta av ljung, kråkris och hjortron. (Strindberg, Hemsöborna 93) 
[...] de même, le fond de la vallée était revêtu d'un épais tapis de bruyère, d'euphorbes et

de fausses-mûres. (110)

Bruket är emellertid inte generaliserat, vilket följande exempel vittnar om:

(11) De gick tillsammans att sätta snaror för fåglarna, metade laxöring i forsen och plockade hjortron på myren. (Lagerlöf, Nils Holgersson 586)

Ensemble ils allaient poser des pièges pour les oiseaux, ils pêchaient des truites dans le torrent et cueillaient des mûres de ronces dans le marécage. (620-1)

Detsamma gäller det i än högre grad exotiska åkerbäret, som i lexika får översättningar som framboise arctique (Hammar), mûre arctique (Zenk), ronce arctique (BlinkenbergHøybye, s. 32).

Däremot har det mindre exklusiva odonbäret en relativt lexikaliserad form, vars beskrivningsvalör, baserad på likhets- och lokalitetsprinciperna, emellertid förblir tämligen vag: airelle des marais (där airelle alldeles uppenbart har betydelsen 'blåbär') (Hammar, Enwall-Lötmarker, Zenk).

Ju mer natur- och kulturspecificiteten hos en företeelse (som i detta fall ett bär) ökar, ju mer ökar benägenheten hos en översättare att i ett läge där någon lexikaliserad form ej finns att tillgå ta sin tillflykt till en typ av adaptering som inte bygger på beskrivningsprincipen, utan snarare på vad man skulle kunna kalla ersättningsprincipen genom parallellism. Ett bra exempel på detta fenomen ger följande mening från Strindbergs Tjänstekvinnans son:

(12) Dagen före ankomsten gick han till skogen och plockade hjortron och blåbär. (Strindberg, Tjänstekvinnans son 79)

La veille de son arrivée il alla au bois cueillir des framboises et des airelles. (80)

Översättaren har här inte gjort något försök att med hjälp av ett beskrivande uttryck hos läsaren av översättningstexten frammana bilden av ett speciellt slags bär. Skälet är givetvis att en sådan beskrivning, hur pertinent den än är, aldrig kan bli effektiv så länge som den referentiella förankringen saknas hos denna läsare. Inför denna hopplösa uppgift har översättaren här i stället valt ett bär om vilket den stora majoriteten fransmän har en mycket klar och väl definierad referentiell kunskap. Denna radikala typ av individuell adaptation är den som Vinay och Darbelnet illustrerar med det klassiska exempel i vilket det specifikt engelska spelet cricket i fransk översättning får motsvaras av cykelloppet Tour de France, med den skillnaden dock att hallon ju ingalunda är något specifikt franskt bär. Det är notervärt att blåbär här inte återgivits med myrtille utan med airelle, vilket förmodligen är en ordagrann översättning och inte något slags omvänd adaptation.

Det är naturligtvis inte heller på något sätt anmärkningsvärt att ordet lingon i fransk översättning adapteras individuellt, vilket då undantagslöst sker med ordet myrtille. Detta kan till och med inträffa i texter där lingon (eller någon dialektal variant av ordet) på andra platser återges med airelle:

(13) Gumman dukade fram ännu en del detaljer. Vinbärsgelé i ena ändan av en salladjär, och lingonsylt i den andra ändan av densamma. (Martinson, Vägen till Klockrike 72) 
La vieille compléta sa table. De la gelée de cassis au bout d'un ravier, de la confiture de myrtilles à l'autre bout. (85)

(14) Över buskgläntan låg solen smörgul och mild och krösentuvorna blänkte. (Moberg, Sömnlös 348)

Un doux soleil couleur de beurre planait au-dessus de la clairière, faisant briller les grappes de myrtilles.(305)

Samma fenomen kan konstateras beträffande andra kulturspecifika bär. Exempelvis återges odonsnår i en och samma text (Martinson, Klockrike) en gång med airelles (145-159) och en annan gång med buisson de myrte (146-159), båda exempel på en adaptation enligt ersättningsprincipen.

Kulturspecifika ord av typen lingon är alltså utsatta för två fundamentalt olika adapteringsstrategier. Lexikografen eftersträvar med nödvändighet en översättning som, i avsaknad av målspråksreferent, så precist som möjligt beskriver källspråksreferenten genom att ta fasta på för denna karakteristiska egenskaper. Översättaren befinner sig i en friare position, där han/hon har möjlighet att antingen anamma de av lexikograferna etablerade, och mer eller mindre lexikaliserade, beskrivande översättningarna, eller att, vid ord med hög kulturspecificitet, välja en icke-beskrivande motsvarighet.

Vi har dock konstaterat att fallet lingon intar en särställning genom att den beskrivande adaptationen där genom reduktion resulterat i en faktisk betydelseförändring, vilken kunde bli möjlig genom utkonkurrerandet av det ena av två synonyma ord, och genom den strävan som finns att i ett sådant läge reducera en adapterad form till ett enkelt lexem då den adapterade formen inte längre fyller någon distinktiv funktion.

\section{(C) Olof Eriksson}

\section{BIBLIOGRAFI}

ARMFELT HANSELL, Ö. (1969), Bärboken, Stockholm, Norstedts.

BLINKENBERG, A. \& HØYBYE, P. (1964), Fransk-Dansk Ordbog, København, H. Hagerup.

BLINKENBERG, A. \& HØYBYE, P. (1991), Dansk-Fransk Ordbog, 4e uppl. København, Handelshøjskolens Forlag \& Nyt Nordisk Forlag Arnold Busck.

BLOCH, O. \& WARTBURG, W. VON (1968), Dictionnaire Étymologique de la Langue

Française, $5^{\mathrm{e}}$ éd., Paris, Presses Universitaires de France.

DAUZAT, A. \& DUBOIS, J. \& MITTERAND, H. (1964), Nouveau Dictionnaire

Étymologique, Paris, Larousse.

Dictionnaire Actuel de la Langue Française (1991), Paris, Flammarion.

Dictionnaire Hachette de la Langue Française (1980), Paris, Hachette.

Duden Français. Bildwörterbuch Deutsch und Französisch (1981), Mannheim-Wien-

Zürich, Duden Verlag.

ENWALL, J. \& LÖTMARKER, R. (1995), Fransk-Svensk Ordbok, Stockholm, Natur och

Kultur.

ERICSSON, J. (1934), Markernas förbisedda guld, Stockholm.

ERIKSSON, L. \& INGELÖG, T. \& KARDELL, L. (1979), Blåbär, lingon, hallon,

Sveriges Lantbruksuniversitet, Avd. för landskapsvård, Rapport 16.

Grand Dictionnaire Encyclopédique Larousse (1982), Paris, Larousse.

Grand Larousse de la Langue Française (1971), t. I, Paris, Larousse.

Le Grand Robert (1989), $2^{\mathrm{e}}$ éd., t. I, Paris, Dictionnaires Le Robert.

HAMMAR, T. (1997), Svensk-Fransk Ordbok, $3^{\mathrm{e}}$ uppl., Stockholm, Norstedts.

KARDELL, L. \& CARLSSON, E. (1982), Hjortron, tranbär, lingon, Sveriges

Lantbruksuniversitet, Avd. för landskapsvård, Rapport 25.

Lexis. Dictionnaire de la Langue Française (1975), Paris, Larousse. 
Micro Robert. Dictionnaire du Français Primordial (1971), Paris, Dictionnaires Le Robert. MISTRAL, F. (1966), Lou Tresor dóu Felibrige ou Dictionnaire Provençal-Français, t. I, Paris, Champion.

MOUNIN, G. (1990), Les problèmes théoriques de la traduction, Paris, Gallimard, Coll.

"Tel".

NEWMARK, P. (1988), A Textbook of Translation, New York-London-Toronto-Sydney-

Tokyo, Prentice Hall.

Norstedts Franska Ordbok (1991), Stockholm, Norstedts.

Le Nouveau Petit Robert (1995), Paris, Dictionnaires Le Robert.

Pluridictionnaire (1975), Paris, Larousse.

Le Robert \& Collins Dictionnaire Français-Anglais (1987), Paris, Dictionnaires Le Robert.

Le Robert Dictionnaire Historique de la Langue Française (1992), t. I, Paris, Dictionnaires

Le Robert.

Le Robert Méthodique (1982), Paris, Dictionnaires Le Robert.

SCHLYTER, B. (1992), Franska Facktermer 10, Lund, Dialogos.

SCHULTHESS, F. (1886), Svensk-Fransk Ordbok, Stockholm, Norstedts.

SVANE, B. (1998), "Comment traduire la réalité? Étude de la traduction des expressions référentielles", Språk- och kulturkontraster. Om översättning till och från franska, (Acta utg. av Olof Eriksson), s. 93-118, Åbo, Åbo Akademis Förlag.

Trésor de la Langue Française (1973), t. 2, Paris, Éditions du C.N.R.S.

Trésor de la Langue Française (1980), t. 8, Paris, Éditions du C.N.R.S.

VINAY, J.P. \& DARBELNET, J (1977), Stylistique comparée du français et de l'anglais, nouvelle édition revue et corrigée, Paris, Didier.

VISING, J. (1936), Fransk-Svensk Ordbok, Stockholm, Norstedts.

WARTBURG, W. VON (1928), Französisches Etymologisches Wörterbuch, Band 1, Bonn, Fritz Klopp Verlag.

WIKMARK, E. (1907), Lingon - om en svensk framtid och om ett fosterländskt företag, Göteborg.

ZENK, G. (1992), Köksfranska. Gastronomisk ordlista, Stockholm, Informationsförlaget.

\section{TEXTER}

BASTIDE, F.-R. (1954), Suède, Paris, Seuil (Coll. "Petite Planète").

BELlessorT, A. (1922), La Suède, Paris, Perrin et $C^{\text {ie }}$ Libraires-Éditeurs.

LAGERKVIST, P. (1961), Gäst hos verkligheten, Bonniers. L'Exil de la terre, Stock, 1977 (övers. Vincent Fournier).

LAGERLÖF, S. (1907), Nils Holgerssons underbara resa genom Sverige, 2, Bonniers. Le merveilleux voyage de Nils Holgersson à travers la Suède, Actes Sud, 1990 (Le Livre de Poche 1991) (övers. Marc de Gouvenain et Lena Grumbach).

MARTINSON, H. (1984), Nässlorna blomma, MånPocket. Les orties fleurissent, Stock, 1978 (övers. C.G. Bjurström et Jean Queval).

MARTINSON, H. (1951), Vägen till Klockrike, Bonniers. Le chemin de Klockrike, Stock, 1951 (övers. Denise et Pierre Naert).

MOBERG, V. (1975), Sömnlös, Bonniers. Insomnie, Nouvelles Éditions Latines, 1948 (övers. Marguerite Gay).

STRINDBERG, A. (1979), Hemsöborna, Bonniers. Les gens de Hemsö, L'Élan, 1991

(övers. Jean-Jacques Robert).

STRINDBERG, A. (1916), Tjänstekvinnans son, Bonniers. Le fils de la servante, Presses

Universitaires de France, 1921 (övers. Camille Polack).

SWAHN, J.-Ö. (1994), Walpurgis, écrevisses et Sainte-Lucie. Fêtes et traditions en Suède, Éditions de l'Institut Suédois (trad. Lydie Rousseau).

WÄGEUS, M. (1986), Jakt på ett vitt fält, Alba. Scène de chasse en blanc, Presses de la Renaissance, 1990 (övers. Jean-Baptiste Brunet-Jailly).

\section{NOTER}

[1] I Lou Tresor dóu Felibrige av Frédéric Mistral (1966, del I, s. 3) uppträder detta bär under namnet abajou : "abajou fruit de l'airelle rouge : 
S'anèren sus la mountagno

Manja arsanos e abajous."

[2] Det finns åtskilliga andra, mera regionala ord för att beteckna blåbäret: brimbelle (östra Frankrike), bleuet (Kanada), luce (Bretagne), moret, etc. (jfr Le Grand Robert, $2^{\mathrm{a}}$ uppl., 1989, del I, s. 222). Airelle och myrtille är emellertid de helt dominerande formerna: "Seuls les mots airelle et myrtille sont connus de la majorité des francophones (sauf au Canada, où l'on dit bleuet)."(Le Grand Robert, 1989, s. 222)

[3] En mini-enkät med fem sedan lång tid i Sverige boende universitetslärare bekräftade detta. Samtliga uppgav det enkla airelle som det ord med vilket de spontant på franska skulle återge det svenska ordet lingon.

[4] I böcker med recept på svenska maträtter är det också airelle som uppträder: [Dolmas de chou = kåldolmar] : "[...] Servir avec des pommes de terre et de la confiture d'airelles" (Swahn, 1994, s. 14). Jämför confiture d'airelles som exempel i Grand Larousse de la Langue Française (1971, s. 109), där det betyder 'blåbärssylt'. 